\title{
The effect of drying treatment on the $n$-alkane analysis
}

\author{
M Oliván, K Osoro
}

Instituto de Experimentación y Promoción Agraria, Apdo 13, 33300 Villaviciosa, Asturias, Spain

\begin{abstract}
$\mathrm{N}$-alkane analysis use to be performed on freeze-dried samples. Sample preparation for routine analysis would be simplified if freezedrying could be replaced by oven-drying. In early work oven-drying was found to reduce the alkane concentration measured in some plant species (Dove and Mayes, 1991, Aust J Agric Res, 42, 913-52). There are not enough information about the effect of different drying treatments on alkane extraction and alkane concentration estimated in faeces and herbage samples.
\end{abstract}

Faeces samples $(n=55)$ of cows dosed with C24, C32 and C36 and lucerne hay samples $(n=33)$ were prepared for the alkane analysis by two procedures : freeze-drying or ovendrying at $40^{\circ} \mathrm{C}$ for $24 \mathrm{~h}$ (herbage) or $48 \mathrm{~h}$ (faeces) to avoid any evaporative loss of alkanes. Samples were extracted by duplicate. Alkane analysis was performed as described by Oliván and Osoro (in this volume).

Alkane concentration was higher in freezedried than oven-dried samples (Table), the difference being significant for shorter chain alkanes (from $\mathrm{C} 24$ to $\mathrm{C} 28$ in faeces, from $\mathrm{C} 25$ to $\mathrm{C} 30$ in herbage). Longer chain alkanes concentration (from $\mathrm{C} 31$ to $\mathrm{C} 36$ ) was only slightly higher when freeze-drying, being the mean discrepancy between the alkane content measured by both drying treatments lower than $3 \%$ in both type of samples. This percentage of discrepancy was similar to that observed between the two replicates of each sample.

Good estimation of C32, C33 and C36 alkanes concentration can be achieved from $40^{\circ} \mathrm{C}$ oven-dried faeces and herbage (lucerne hay) samples. Therefore oven-drying would not affect on the estimation of herbage intake and digestibility, being an easier procedure than freeze-drying.

However, diet composition studies, estimated from a wide range of alkanes (from C21 to C35) in faeces and herbage samples should require freeze-drying.

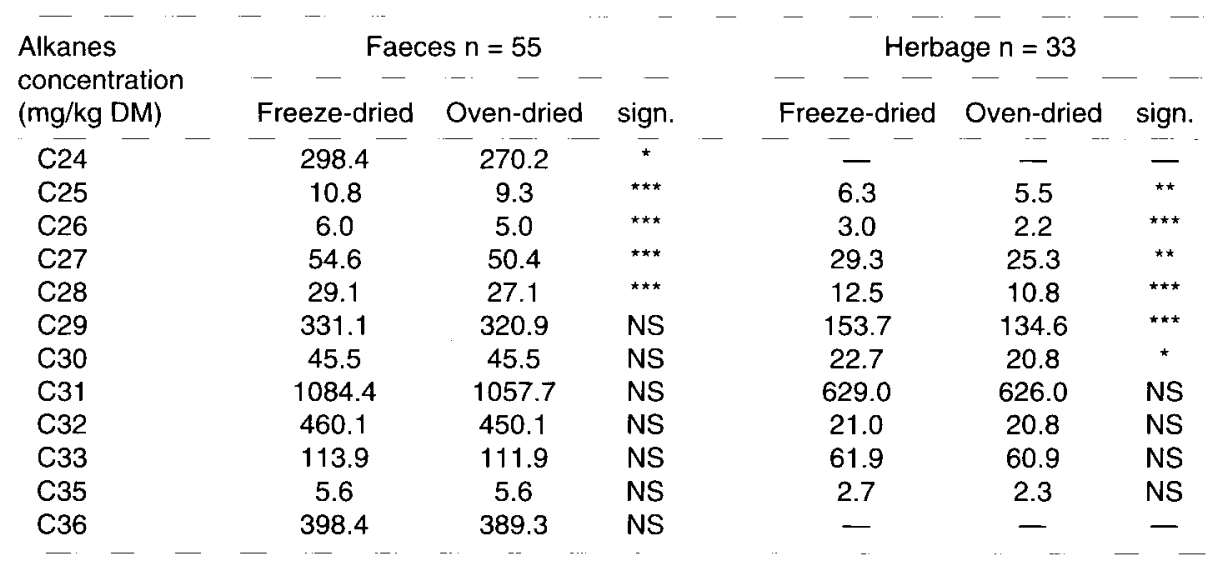

